\title{
Effect of Pretreatment Film Composition on Adhesion of Organic Film on Zinc Coated Steel Sheet*1
}

\author{
Akira Matsuzaki $^{1}$, Masaaki Yamashita ${ }^{1, * 2}$ and Nobuyoshi Hara ${ }^{2}$ \\ ${ }^{1}$ Steel Research Laboratory, JFE Steel Corporation, Kawasaki 210-0855, Japan \\ ${ }^{2}$ Department of Materials Science, Tohoku University, Sendai 980-8579, Japan
}

It is known that chromate pretreatment films with dry-type silica adhere well to organic films such as paint and laminate films on a zinc coated steel sheet. The role of surface polarity in the adhesion mechanism has been investigated for a long time, but remains unclear. We examined the correlation between the composition of chromate pretreatment films with dry-type silica and their adhesion to a laminate film on a zinc coated steel sheet, for both the wet silica and without silica types of chromate pretreatment film. We also investigated the adhesion mechanism by analyzing the pretreatment films using SEM, AFM, BET, TEM and EDX.

The results were as follows. Not only the type and particle size of silica, but also the silica/chromate ratio and the coexistence of chromate affected the adhesion of laminate films. The highest adhesive strength was obtained for the pretreatment films formed in a pretreatment solution with $\mathrm{SiO}_{2} / \mathrm{Cr}$ ratio of 4.0 and dry-type silica with a particle diameter of $7 \mathrm{~nm}$. The good adhesion of chromate pretreatment films with dry-type silica is due to an anchor effect by sub-micron surface roughness and an increased number of interface bonding sites by a nano-porous structure. The formation of an insoluble $\mathrm{Cr}(\mathrm{III})$ compound layer plays an important role in binding silica particles to the zinc coating surface. [doi:10.2320/matertrans.M2010185]

(Received May 24, 2010; Accepted July 6, 2010; Published August 19, 2010)

Keywords: adhesion, morphology, microstructure, zinc coated steel sheet, dry-type silica, chromate, pretreatment, laminate, atomic force microscope, BET method, transmission electron microscope

\section{Introduction}

Surface finishing has been widely applied to steel materials to confer various functions such as corrosion resistance and ease of design at low cost. In order to make these functions remain effective for a long time, it is important to enhance the adhesion between the surface finishing layers such as metal plating, paint and laminate film at the interface or between these layers and the substrate. For painted or laminated steel sheets which have been widely applied to building materials and electrical appliances, the adhesion between paint or laminate films and zinc coatings has been greatly improved to reduce maintenance and improve the design, and the adhesion mechanism has been actively investigated.

Zinc phosphate treatment has been used to pretreat zinc coated steel sheet since the early 1950s. Zinc phosphate films, which are formed by the reaction of zinc and its treatment solution, are crystalline and porous. Their good adhesion is due to the anchor effect of holes which account for 0.1 to $10 \%$ of the total surface area. Since the crystal size of zinc phosphate affects the adhesion and corrosion resistance, surface adjustment and post-treatment are required. Surface adjustment is used to achieve adsorption of a titanium compound to decrease the size of zinc phosphate particles on the zinc coating by promoting nucleus formation, while in the posttreatment a chromate film is coated after the zinc phosphate treatment to achieve a seal. Thus, zinc phosphate treatment involves a complicated process. Accordingly, the dry-in-place chromate treatment was developed in the late 1980s. Since the chromate film is formed by drying a zinc coated steel sheet

\footnotetext{
*1 This Paper was Originally Published in Japanese in J. Japan Inst. Metals 73 (2009) 475-483.

${ }^{*}$ Present address: Analysis and Characterization Division, JFE TechnoResearch Corporation
}

which is coated with the treatment solution, treatment is easier than zinc phosphate treatment. Since the dry-in-place chromate treatment requires no washing process, unlike reactin-place and electrolysis chromate treatments, large-scale effluent treatment facilities are also unnecessary. Further, by adding phosphoric acid, silica and resin, this treatment can provide various functions such as anti-fingerprint, paint adhesion and lubrication, and so it is now widely used.

Paint adhesion is known to depend on the amount and type of silica in the chromate layer. It has been reported that optimizing the amount of silica caused it to condense on the surface of chromate films, and that the dry- or chain-type silica improves the paint adhesion. ${ }^{1-5)}$ The adhesion mechanism involves many factors related to surface polarity, which is attributed to intermolecular forces such as hydrogen bonding. For example, the surface energy of a dry-in-place chromate film with silica and phosphoric acid was measured by the contact angle of water or methylene iodide, and the paint adhesion was considered to be influenced by the ratio of the polarity force and dispersion force to the film composition. ${ }^{6-8)}$ The results showed that adhesion is improved because the silica condenses toward the upper part of the film and the polarity component is increased. However, the superior adhesion of dry-type silica which has fewer silanol groups, which are the polarity groups on the silica surface, compared with wet-type silica in terms of manufacturing method cannot be explained by these considerations based on surface polarity alone. Moreover, the role of chromate in adhesion is not clear. On the other hand, in view of environmental regulations such as the RoHS Directive, chromate-free coatings are required for the pretreatment films of organic films such as paint and laminate films. Understanding how chromate and silica improve adhesion would assist the design of chromate-free films. In this work, we examined the correlation between the composition of 
Table 1 Composition of pretreatment solutions.

\begin{tabular}{cccc}
\hline \multirow{2}{*}{ Treatment type } & $\mathrm{Cr}(\mathrm{VI}) / \mathrm{Cr}(\mathrm{III})$ & \multicolumn{2}{c}{ Silica } \\
\cline { 3 - 4 } & & \multicolumn{2}{c}{ Production Type } \\
\hline $\mathrm{A}$ & + & - & - \\
\hline $\mathrm{B}$ & - & + & Dry \\
\hline $\mathrm{C}$ & + & + & Wet \\
\hline $\mathrm{D}$ & + & & Dry \\
\hline E & & Zn phosphate coating & \\
\hline +: Constituent & & &
\end{tabular}

chromate pretreatment films with dry-type silica and their adhesion to an organic film on a zinc coated steel sheet. The sub-micron morphology was also considered.

\section{Experimental}

\subsection{Specimens}

The basic composition of the pretreatment solutions is shown in Table 1. Partially reduced chromic acid solutions were prepared by reducing $\mathrm{Cr}$ (VI) to $\mathrm{Cr}$ (III) by adding cane sugar to chromic acid solution $(50 \mathrm{~g} / \mathrm{L})$ till the $\mathrm{Cr}$ (III) $/ \mathrm{Cr}$ (VI) mass ratio became 40/60. Both dry- and wet-type $\mathrm{SiO}_{2}$ were used. In the basic condition, the primary particle size of silica is $12 \mathrm{~nm}$. Treatment type solutions C and D were prepared by adding $\mathrm{SiO}_{2}$ to partially reduced chromic acid solution till the $\mathrm{SiO}_{2} / \mathrm{Cr}$ ratio became 4.0. Furthermore, pretreatment solutions with varying $\mathrm{SiO}_{2} / \mathrm{Cr}$ mass ratio and particle size of silica were prepared as treatment type $\mathrm{D}$. The $\mathrm{SiO}_{2} / \mathrm{Cr}$ mass ratio in this paper means the ratio of $\mathrm{SiO}_{2}$ concentration (mass\%) to metallic $\mathrm{Cr}$ concentration (mass\%) in the treatment solutions and the ratio of films is varied with the ratio of solutions. As a comparison, zinc phosphate film (treatment type E, coating weight: $2.0 \mathrm{~g} / \mathrm{m}^{2}$ ), which is widely used as the pretreatment layer for laminated steel sheet, was prepared.

The specimens were prepared by drying (peak metal temperature: $120^{\circ} \mathrm{C}$ ) after coating these solutions on hot-dip zinc coated steel sheets (sheet thickness: $0.5 \mathrm{~mm}$, zinc coating weight: $120 \mathrm{~g} / \mathrm{m}^{2}$ at one side) by a bar coater. The basic $\mathrm{Cr}$ coating weight of treatment types $\mathrm{A}, \mathrm{C}$ and $\mathrm{D}$ was $35 \mathrm{mg} / \mathrm{m}^{2}$ as metallic $\mathrm{Cr}$. The basic $\mathrm{SiO}_{2}$ coating weight of treatment types B, C and D was $140 \mathrm{mg} / \mathrm{m}^{2}$. These coating weights were controlled by the concentration and wet amount of the pretreatment solutions.

\subsection{Evaluation of adhesion}

Adhesion was evaluated using laminated specimens. The structure of specimens used for the adhesion test is shown in Fig. 1. These specimens were prepared by crimping vinyl chloride films (thickness: $3 \mu \mathrm{m}$ ) at $200^{\circ} \mathrm{C}$ after forming olefin adhesive films on these specimens.

Adhesion was evaluated by two methods, as shown in Fig. 2.

\subsubsection{Peel-off strength after stretching}

The peel-off strength was measured by peeling off the laminate film of $2 \mathrm{~cm}$ width after stretching the specimen to $20 \%$ of its length.

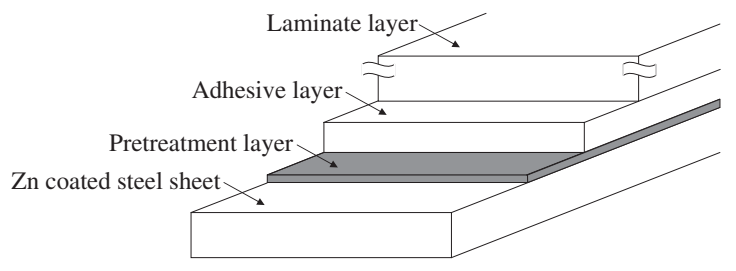

Fig. 1 Structure of specimen used for adhesion tests.

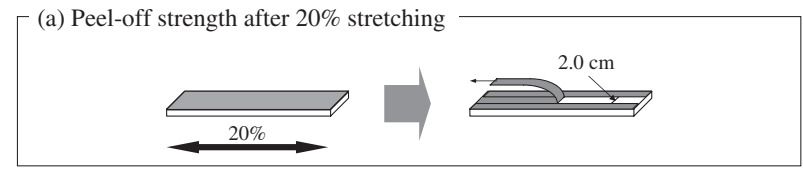

(b) Rating of adhesion at bent section after $20 \%$ stretching and heating -
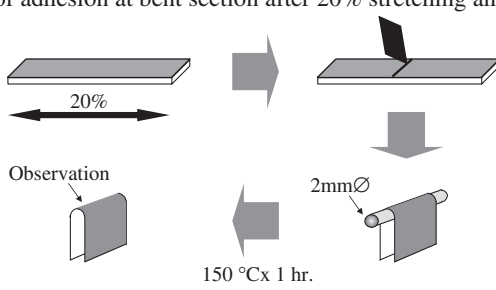

Fig. 2 Evaluation methods of film adhesion strength.

\subsubsection{Adhesion at bent section}

Adhesion at the bent section was evaluated by categorizing the extent of film exfoliation into five levels after heating $\left(150^{\circ} \mathrm{C} \times 1 \mathrm{~h}\right)$ the specimens after cutting off the laminate film with a knife and bending the specimens around a metallic bar (diameter: $2 \mathrm{~mm}$ ). The extent of film exfoliation was rated as five points when the film on both sides, which had been cut off by a knife, stuck to the steel sheet after heating, and was rated as one point when these films exfoliated in parallel without following the steel sheet after heating. If the extent could not be judged according to this rating, it was evaluated by categorizing the area of exfoliated film according to three levels. The grades were defined by the average of two specimens having the same film composition.

Furthermore, C and Si X-ray images of the exfoliated parts of the specimens after evaluating the peel-off strength were measured by EPMA in order to identify the exfoliation face (measurement area: $1.0 \times 1.0 \mathrm{~mm}$ ).

\subsection{Analysis of film structure}

Structural analysis of the pretreatment films was carried out by the following methods.

\subsubsection{Analysis of surface structure}

Secondary ion images of the specimen surfaces were observed by FE-SEM (Hitachi S-510). These images were taken by tilting the specimens at 30 degrees (acceleration voltage: $2 \mathrm{kV}$ ).

The AFM images of these surfaces were observed by AFM (Digital Instrument Nano Scope II). The following roughness parameters were calculated from the cross-sectional profiles (length: $7000 \mathrm{~nm}$ ).

Average roughness $\left(R_{\mathrm{a}}\right)$ : average of roughness curve for center line

Maximum height $\left(R_{\max }\right)$ : height difference between highest point and lowest point 


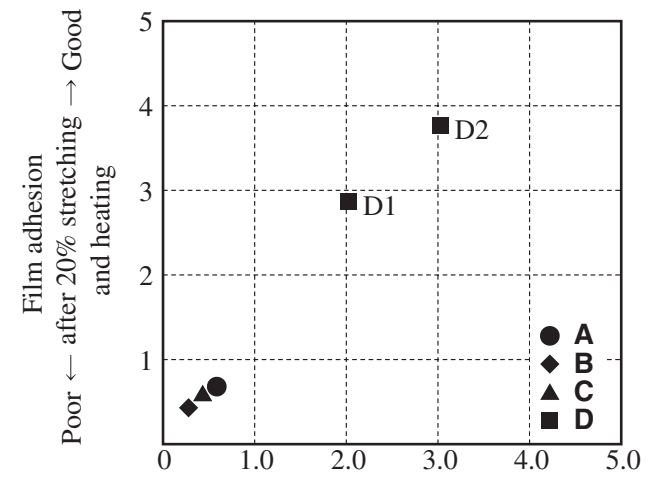

Peel-off strength after $20 \%$ stretching, $N / \mathrm{kgf}$

Fig. 3 Influence of pretreatment composition on film adhesion. (A, C, D) Cr coating weight: $45 \mathrm{mg} / \mathrm{m}^{2},(B, C, D) \mathrm{SiO}_{2}$ coating weight: $180 \mathrm{mg} / \mathrm{m}^{2}$.

\subsubsection{Measurement of specific surface area}

The specific surface areas of the specimens were measured by the BET multi-point method. The BET specific surface areas were calculated by applying multi-molecular adsorption theory to the adsorption isotherm of $\mathrm{Kr}$ at $77 \mathrm{~K}$, which was obtained by automatic gas adsorption measurement (BEL Japan BELSOP36). The molecular occupied area of $\mathrm{Kr}$ used in this measurement is estimated to be $0.2 \mathrm{~nm}^{2}$ at $77 \mathrm{~K}$, which is regarded as the lower limit of detection (resolving power) in the measurement result by this method. The specific surface area of the hot-dip zinc coated steel sheet was 1.1 .

\subsubsection{Analysis of cross-sectional structure and its com- position}

Cross-sectional specimens were prepared by the microtome method. Morphology observation by cross-sectional TEM images (acceleration voltage: $250 \mathrm{kV}$ ) and composition analysis by EDX were carried out by TEM (Philips CM30T).

\section{Results}

\subsection{Evaluation of adhesion}

The peel-off strength after $20 \%$ stretching and adhesion at the bent section of the laminated specimens are shown in Fig. 3. The chromate pretreatment films with dry-type silica D group (D1 and D2) exhibited remarkably high peel-off strength and film adhesion in comparison with the chromate (silica-free) pretreatment film A, dry-type silica (chromatefree) pretreatment film B and chromate pretreatment film with wet-type silica $\mathrm{C}$. In particular, $\mathrm{D} 2\left(\mathrm{SiO}_{2}\right.$ particle size: $12 \mathrm{~nm}, \mathrm{SiO}_{2} / \mathrm{Cr}$ mass ratio: 4.0) exhibited higher adhesion than $\mathrm{D} 1\left(\mathrm{SiO}_{2}\right.$ particle size: $700 \mathrm{~nm}, \mathrm{SiO}_{2} / \mathrm{Cr}$ mass ratio: 1.5), which simulated the commercial pretreatment films for paint undercoats. Thus, not only the type and particle size of silica but also the silica/chromate ratio and the coexistence of chromate greatly affect the adhesion of laminate films.

The effects of $\mathrm{SiO}_{2}$ particle size, $\mathrm{SiO}_{2} / \mathrm{Cr}$ mass ratio and $\mathrm{Cr}$ coating weight on adhesion were investigated using chromate pretreatment films with dry-type silica D. Figures 4 and 5 show the influence of $\mathrm{SiO}_{2} / \mathrm{Cr}$ ratio and size of $\mathrm{SiO}_{2}$ particles in pretreatment solutions on peel-off strength and Figs. 6 and 7 show the influence of $\mathrm{SiO}_{2} / \mathrm{Cr}$ ratio and size of $\mathrm{SiO}_{2}$ particles in pretreatment solutions on rating of

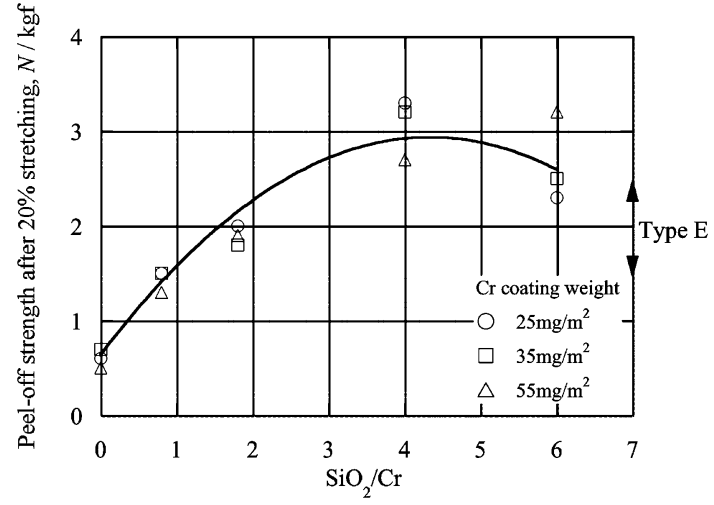

Fig. 4 Influence of $\mathrm{SiO}_{2} / \mathrm{Cr}$ ratio of pretreatment solutions on peel-off strength.

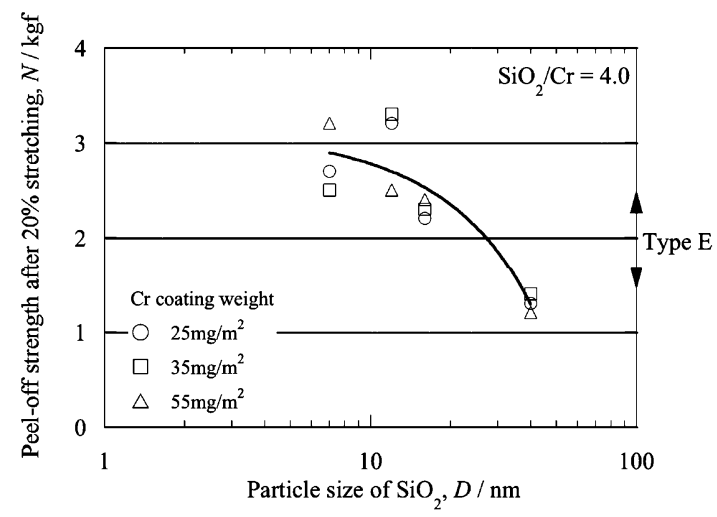

Fig. 5 Influence of size of $\mathrm{SiO}_{2}$ particles in pretreatment solutions on peeloff strength.

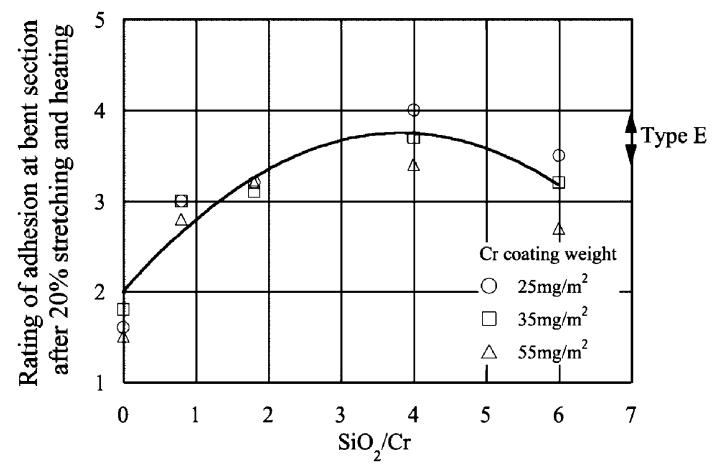

Fig. 6 Influence of $\mathrm{SiO}_{2} / \mathrm{Cr}$ ratio of pretreatment solutions on rating of adhesion.

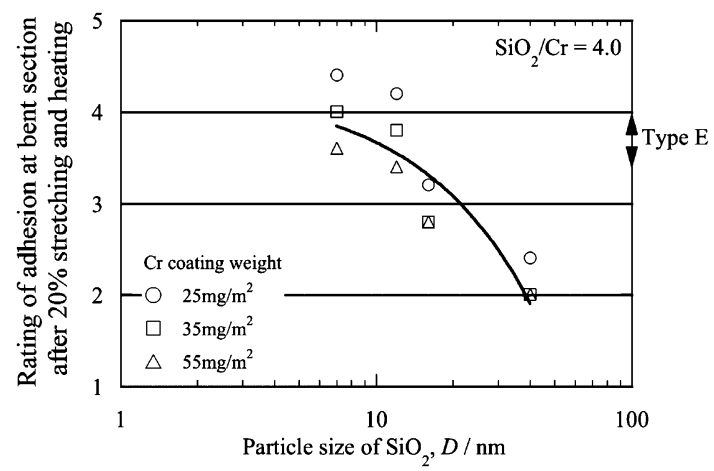

Fig. 7 Influence of size of $\mathrm{SiO}_{2}$ particles in pretreatment composition on rating of adhesion. 


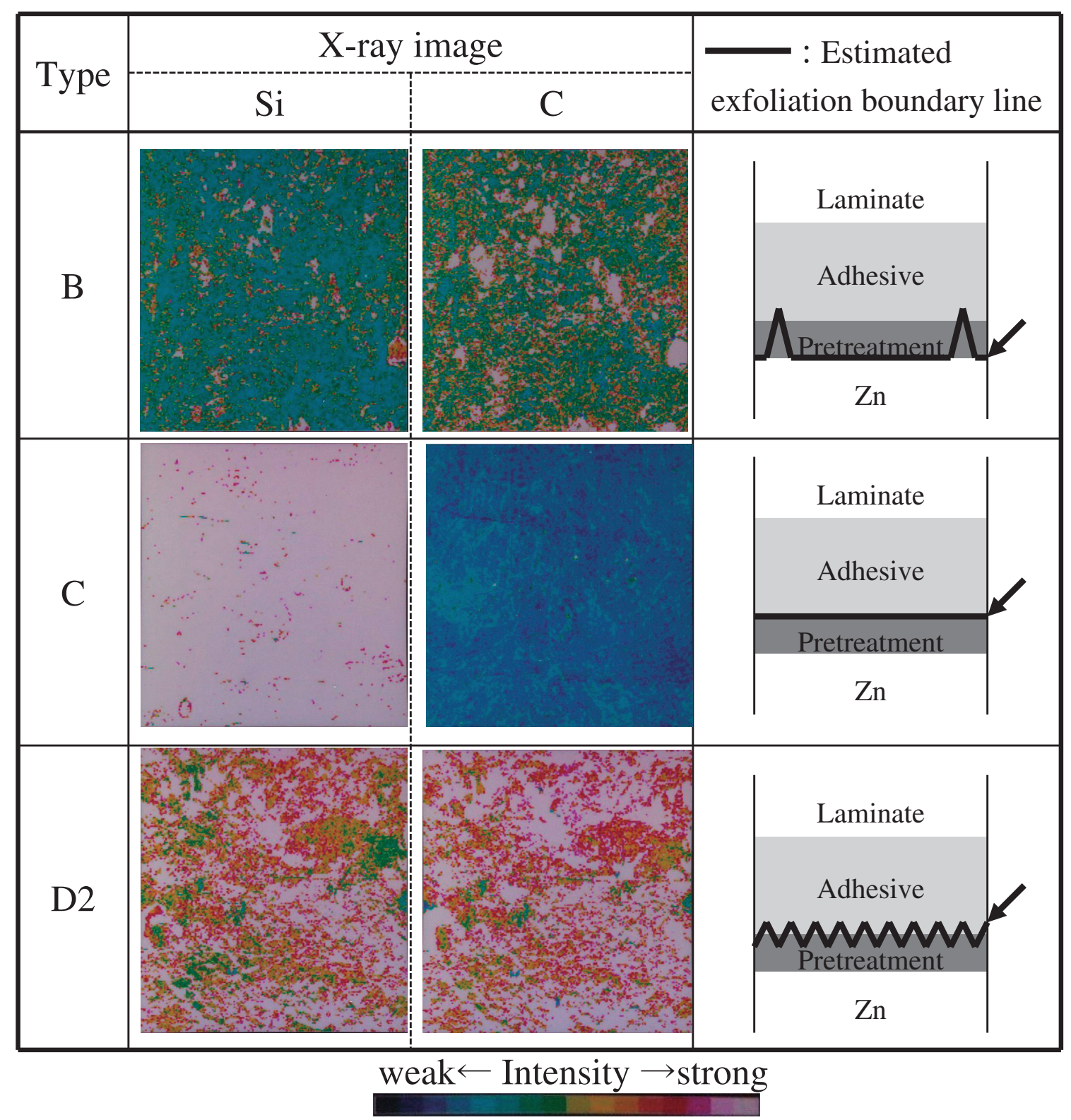

Fig. 8 EPMA elemental mapping at exfoliated parts of specimens after peel-off tests.

adhesion, respectively. The results for the zinc phosphate pretreatment film (treatment type E) are included in the figures. The peel-off strength increased and the adhesion at the bent section improved as the $\mathrm{SiO}_{2}$ particle size decreased. It was found that these properties declined when the $\mathrm{SiO}_{2} / \mathrm{Cr}$ mass ratio was over 4.0 and hardly changed when the $\mathrm{Cr}$ coating weight was between 20 and $55 \mathrm{mg} / \mathrm{m}^{2}$. According to these results, the adhesion of the chromate pretreatment films with dry-type silica $\mathrm{D}$ depends on $\mathrm{SiO}_{2}$ particle size and $\mathrm{SiO}_{2} / \mathrm{Cr}$ mass ratio, and does not depend on the $\mathrm{Cr}$ coating weight between 20 and $55 \mathrm{mg} / \mathrm{m}^{2}$. The highest adhesive strength was obtained for the pretreatment film with $\mathrm{SiO}_{2} / \mathrm{Cr}$ ratio of 4.0 and dry-type silica with a particle diameter of $7 \mathrm{~nm}$, which was equivalent to the conventional zinc phosphate film.

Figure 8 shows X-ray images of the surface of the substrates by EPMA after evaluating the peel-off strength. In the case of the dry-type silica pretreatment film $\mathrm{B}$, the intensity of $\mathrm{Si}$, which is thought to derive from the pre- treatment film component, and the intensity of $\mathrm{C}$, which is thought to derive from the adhesive layer, were generally low. However, parts on which both elements were detected at high intensity were also recognized. Furthermore, the intensity of $\mathrm{Cl}$, which is thought to derive from the laminate film, was low for the same part. These results suggest that the exfoliation mode of this specimen is predominantly interface exfoliation between the pretreatment film and the zinc coating, and that cohesive destruction in the adhesive film partly occurred.

In the case of the chromate pretreatment film with wet-type silica $\mathrm{C}$, it was found that the intensity of $\mathrm{Si}$ was strong and that of $\mathrm{C}$ was weak overall. These results suggest that the exfoliation mode is interface exfoliation between the adhesive film and the pretreatment film.

In the case of the chromate pretreatment film with dry-type silica D2, it was found that the intensities of both Si and C were strong and that the parts of high intensity of Si almost matched the parts of high intensity of $\mathrm{C}$. It can therefore be 
presumed that the exfoliation mode is cohesive destruction across the interface between the pretreatment film and the adhesive film.

\subsection{Film analysis}

\subsubsection{Analysis of surface structure}

SE images of the surfaces of the specimens by FE-SEM are shown in Fig. 9. The dry-type silica (chromate-free) film B and the chromate pretreatment film with dry-type silica D2 have fine surface roughness in comparison with the chromate (silica-free) film A and the chromate pretreatment film with wet-type silica $\mathrm{C}$. The chromate pretreatment film with drytype silica D2 shows a high coverage and uniformity with rough parts. In contrast, the dry-type silica (chromate-free) film shows a low coverage and even has parts where the substrate is exposed.

AFM images, cross-sectional profiles and the roughness parameter $\left(R_{\mathrm{a}}, R_{\max }\right)$ on these diagonals of the specimen surfaces are shown in Fig. 10. It was found that the chromate pretreatment film with dry-type silica D2 had rough surface in comparison with the chromate (silica-free) film $\mathrm{A}$ and the chromate pretreatment film with wet-type silica $\mathrm{C}$ as shown in Fig. 9, and that its $R_{\max }$ value was approximately $400 \mathrm{~nm}$.

Since the $\mathrm{SiO}_{2}$ particle size and $\mathrm{SiO}_{2} / \mathrm{Cr}$ mass ratio greatly influence the adhesion, SE images and AFM cross-sectional profiles of the specimens for varying $\mathrm{SiO}_{2}$ particle size and $\mathrm{SiO}_{2} / \mathrm{Cr}$ mass ratio were observed.

SE images and AFM cross-sectional profiles of the chromate pretreatment films with dry-type silica with a primary particle size of $12 \mathrm{~nm}$ or $40 \mathrm{~nm} D$ are shown in Fig. 11. There was a large difference in adhesion between the two specimens. Though these surfaces had fine surface roughness, there was no large difference in morphology. SE images of the chromate pretreatment film with dry-type silica and with $\mathrm{SiO}_{2} / \mathrm{Cr}$ mass ratio of 1.5 or 4.0 are shown in Fig. 12. It is found that the flat substrate area is exposed in the case of $\mathrm{SiO}_{2} / \mathrm{Cr}=1.5$ and that there is a uniform covering of rough films in the case of $\mathrm{SiO}_{2} / \mathrm{Cr}=4.0$.

\subsubsection{Measurement of specific surface area}

The specific surface areas of the chromate pretreatment films with dry-type silica $\mathrm{D}$ for varying primary particle size of $\mathrm{SiO}_{2}$ are shown in Fig. 13, measured by the BET multipoint method. Though it is not possible to clarify any difference in surface roughness between the particle size of $12 \mathrm{~nm}$ and that of $40 \mathrm{~nm}$ by SE images and AFM images in Fig. 11, it was found that the specific surface area remarkably increased as the primary particle size of dry-type silica decreased.

\subsubsection{Analysis of cross-sectional structure and composi- tion}

TEM images of the cross-sectional specimen of the chromate pretreatment film with $\mathrm{SiO}_{2} / \mathrm{Cr}$ mass ratio of 4.0 and dry-type silica with a particle diameter of $12 \mathrm{~nm}$ are shown in Fig. 14. Dark parts were observed and the crystal silica was condensed in the D2 coating which had a thickness of approximately $0.3 \mu \mathrm{m}$. The depth profile of the film, which was measured by EDX, is shown in Fig. 15. It was found that $\mathrm{Cr}$ condensed toward the interface between the D2 film and zinc coating and that $\mathrm{SiO}_{2}$ condensed toward the interface between the adhesive film and D2 film.

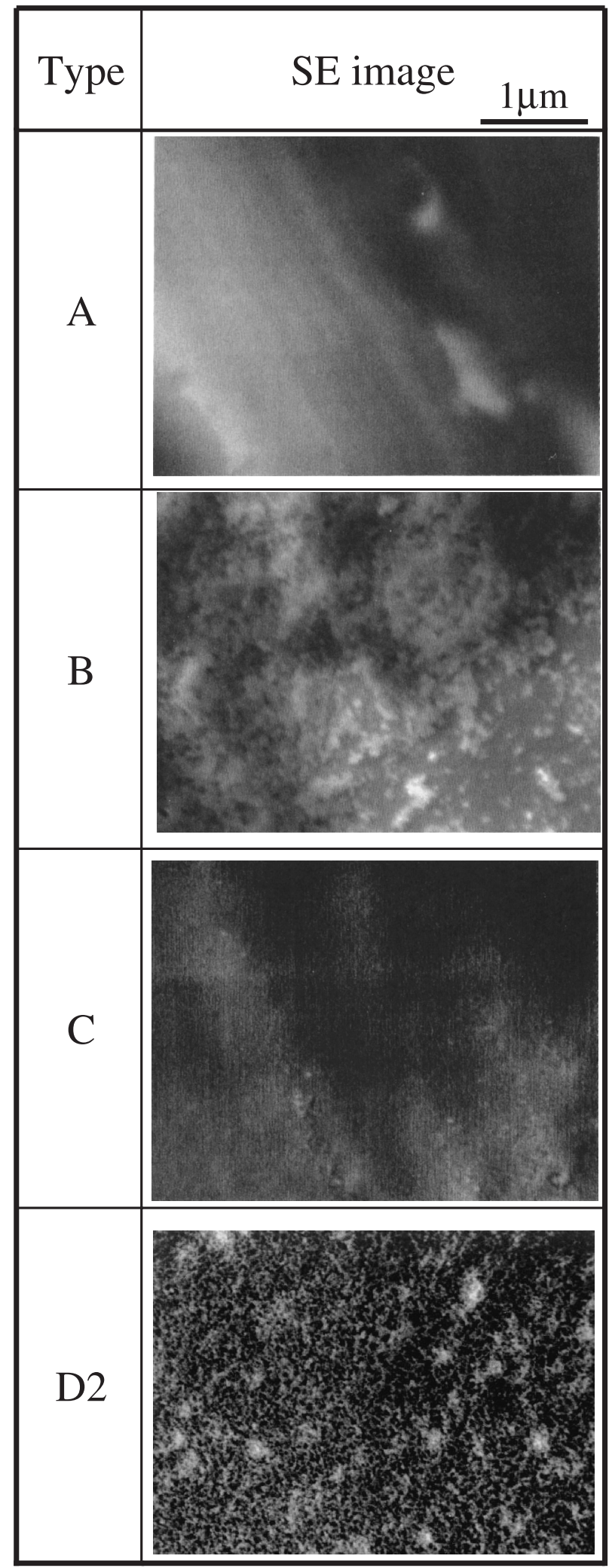

Fig. 9 SE images of pretreatment surface.

The state transition of $\mathrm{Cr}$ with depth of the chromate films was observed by XPS measurement of obliquely polished cross-sectional specimens, ${ }^{9)}$ XPS measurement with ion sputtering, ${ }^{10)}$ and XPS measurement using synchrotron radiation as the X-ray source, ${ }^{11)}$ which has a wide energy range and high luminance. All results indicated that $\mathrm{Cr}$ (III) condenses in the lower part of the chromate film near the zinc 


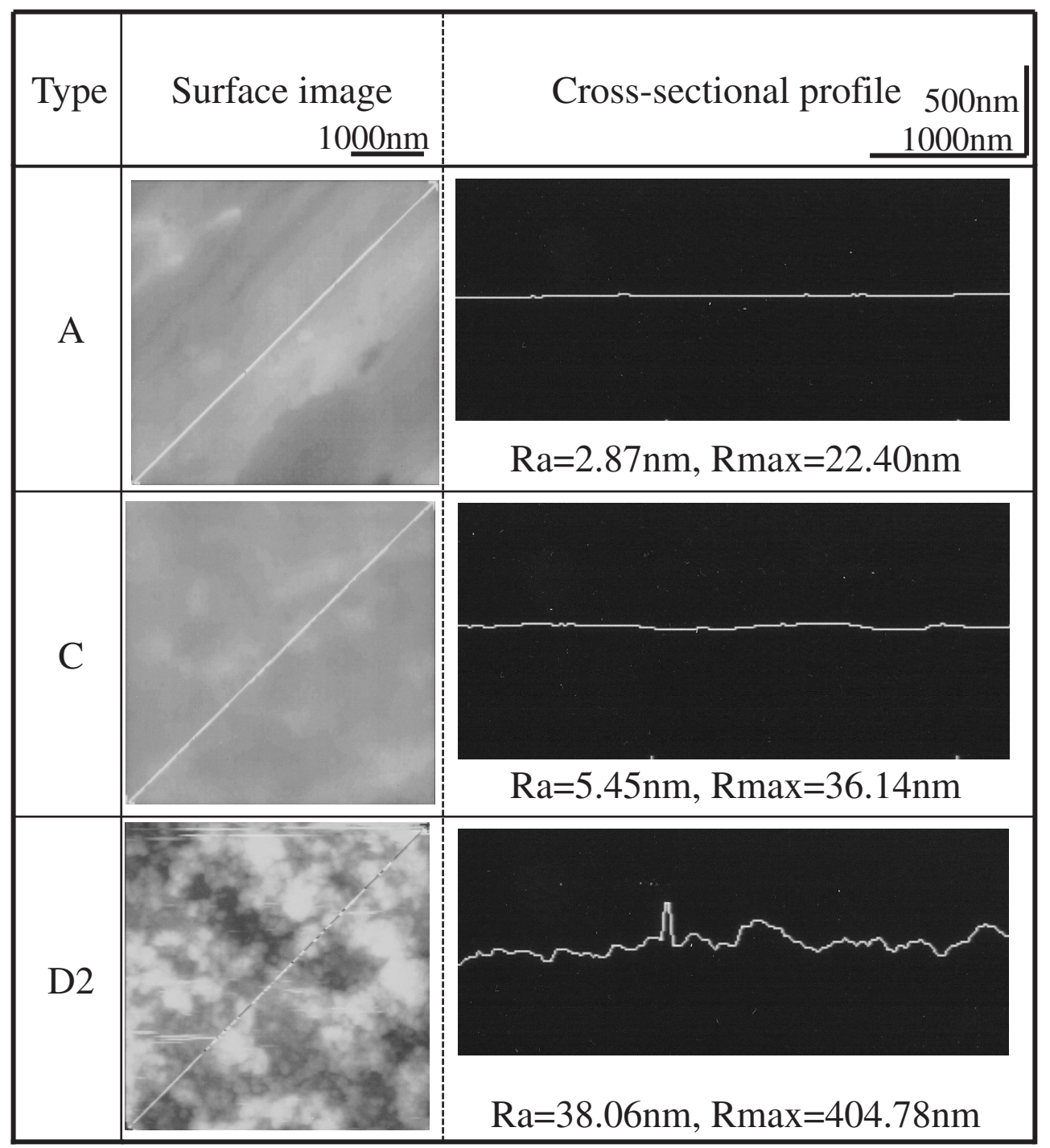

Fig. 10 Surface morphology of pretreatment layers by AFM.

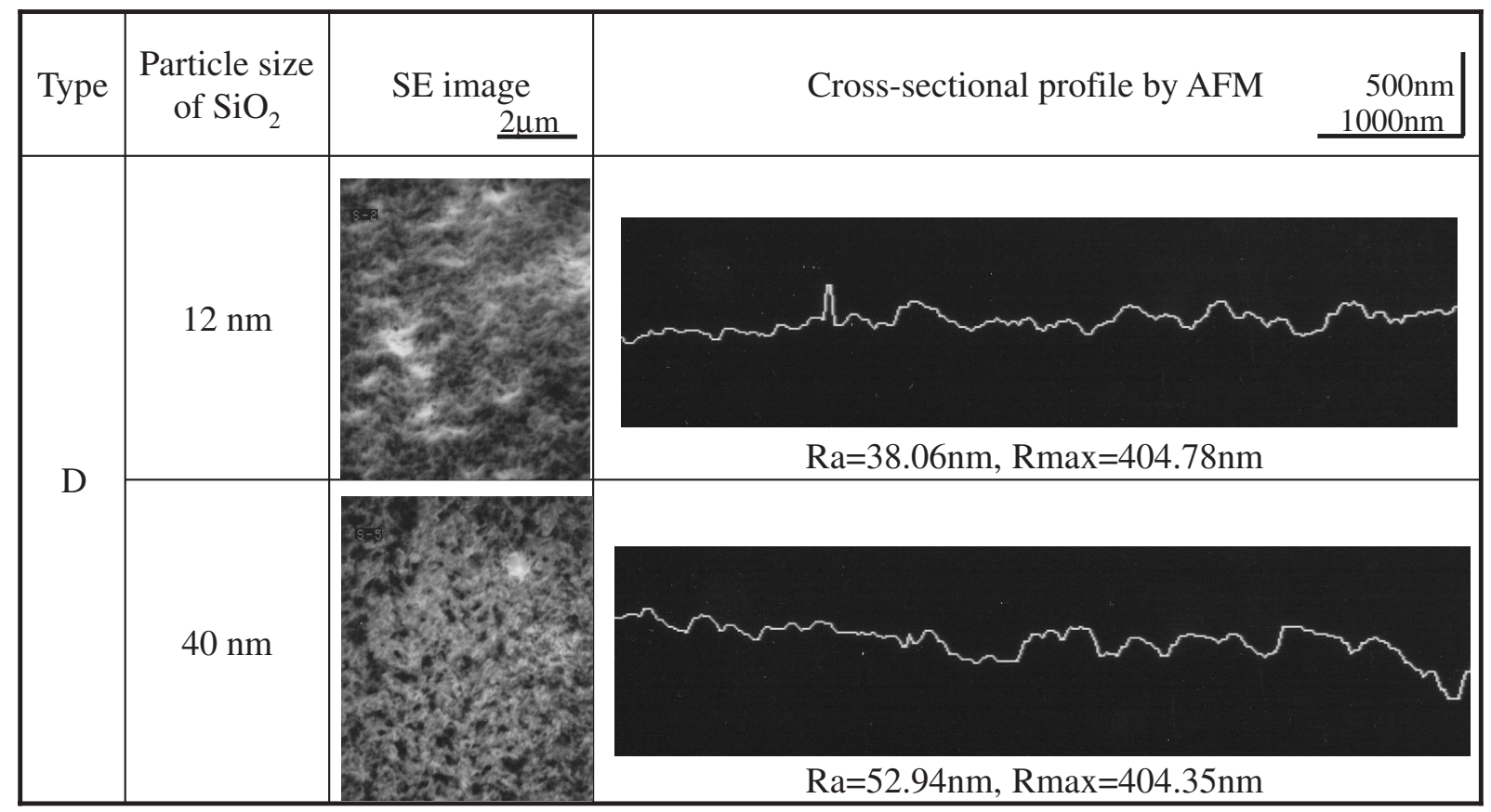

Fig. 11 Influence of $\mathrm{SiO}_{2}$ particle size on surface morphology of type D treated samples. 
coating and that $\mathrm{Cr}(\mathrm{VI})$ condenses in the upper part. With the D2 film, the $\mathrm{Cr}$ that condensed near the interface between the

D2 film and zinc coating seemed to be Cr(III).

\section{Discussion}

\subsection{Improved adhesion by adding dry-type silica}

Venables et al. ${ }^{12)}$ investigated the adhesion mechanism of

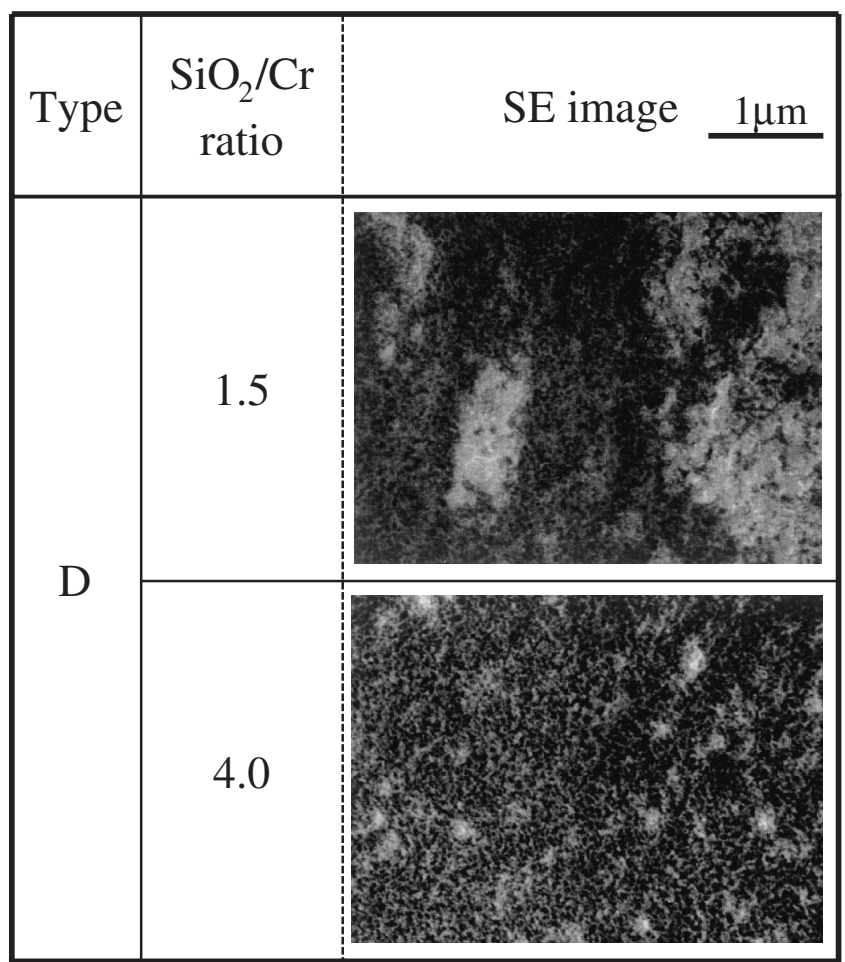

Fig. 12 SE images of pretreatment surface of type D treated samples. pretreatment for $\mathrm{Al}$ and found that fine surface roughness at submicron level was formed on the surface of Al by high resolution SEM and concluded that the adhesion resulted from an anchor effect between the porous oxide film and adhesive because there was a correlation between the fineness of the surface roughness and the adhesion. It is thought that a zinc phosphate coating, which has long been used as a pretreatment film for paint undercoats, produces adhesion by the anchor effect of zinc phosphate crystals at the micron level.

According to morphology analysis by SEM and AFM, since the chromate pretreatment film with dry-type silica D group, which was shown to have good adhesion, has fine surface roughness, it is thought that its roughness contributes to the anchor effect and that the good adhesion results from cohesive destruction across the interface between the pretreatment film and the adhesive film. In the case of the chromate pretreatment film with wet-type silica $\mathrm{C}$ where fine surface roughness was not observed, since the anchor effect was not exhibited and exfoliation occurred at the interface

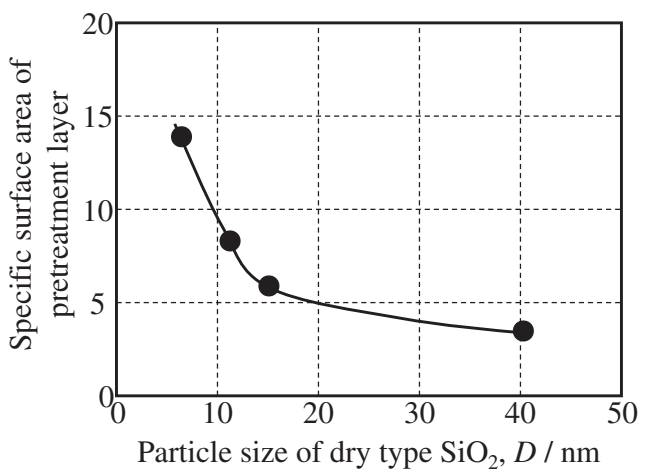

Fig. 13 Influence of $\mathrm{SiO}_{2}$ particle size on specific surface area.
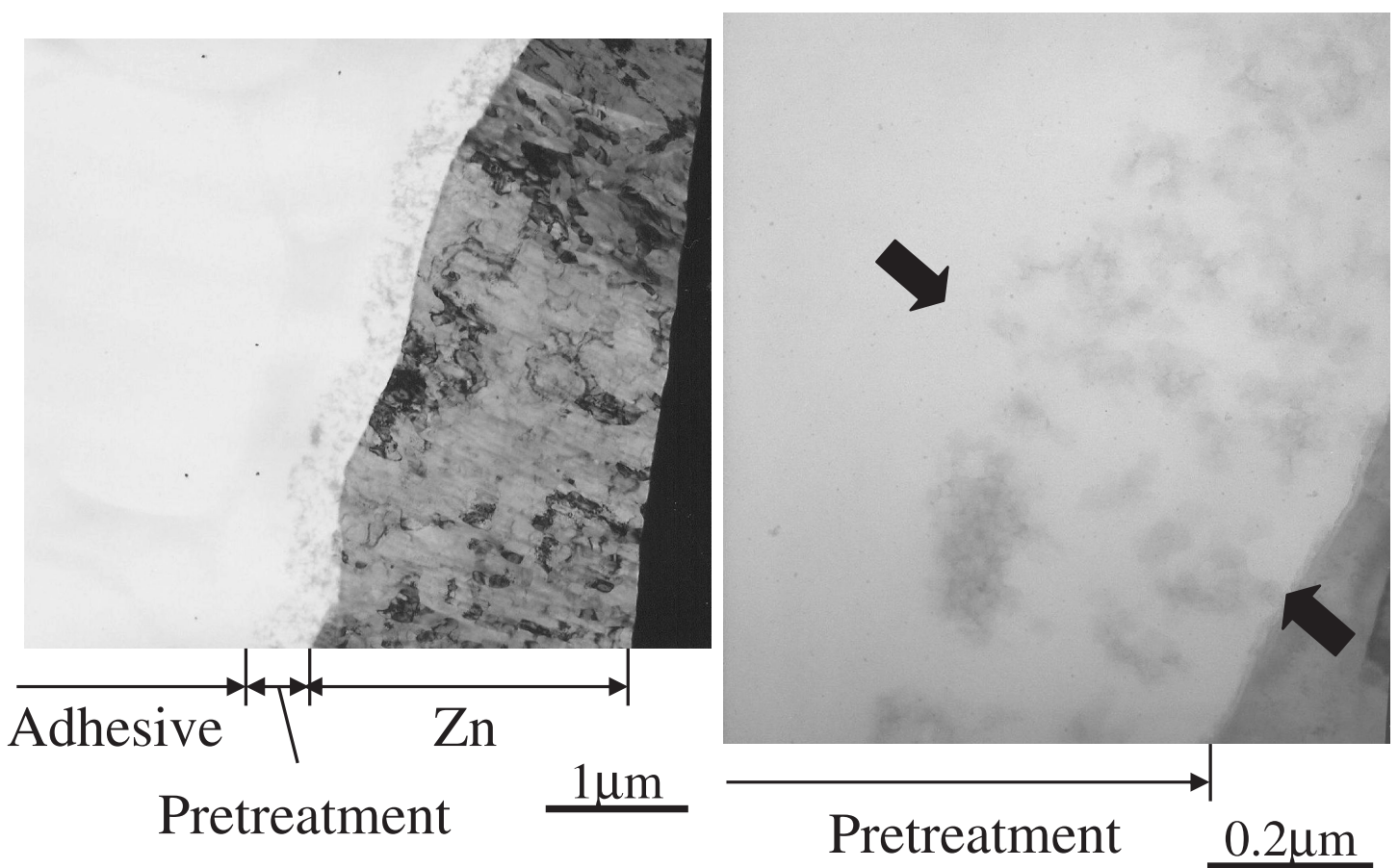

Fig. 14 Cross-sectional TEM image of a type D treated sample. 


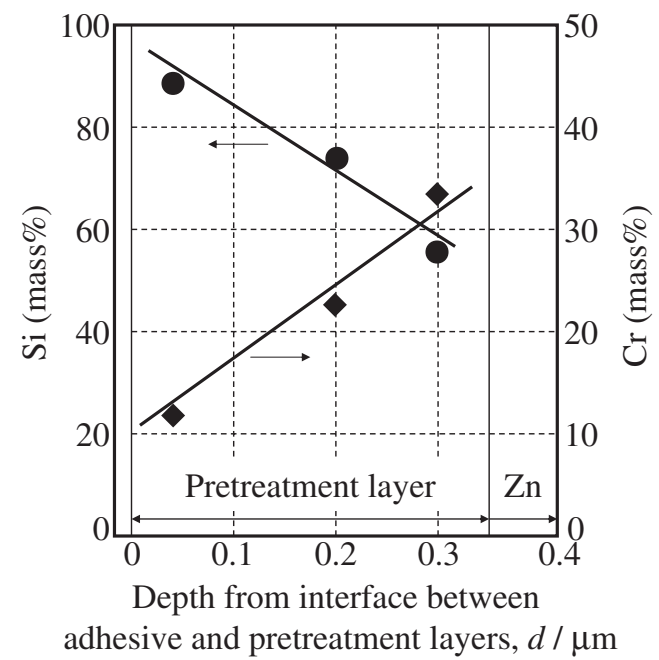

Fig. 15 Depth profile of $\mathrm{Si}$ and $\mathrm{Cr}$ in pretreatment layer (Type D treated sample).

between the pretreatment film and the adhesive film as shown in Fig. 8, adhesion was poor and equivalent to chromate pretreatment film A. These morphological differences by type of silica are thought to be due to the differences of silanol density on the surface of silica, resulting from the differences in manufacturing method. Namely, the dry-type silica, which is manufactured by flame hydrolysis which is a dry process, has a lower surface density of $\mathrm{OH}$ groups than the wet-type silica, which is manufactured by an ion exchange method, etc., which is a wet process. It has been reported that the $\mathrm{OH}$ group density of dry-type silica was 2.6 pieces $/ \mathrm{nm}^{2}$ and that of wet-type silica was 5.7 pieces/ $\mathrm{nm}^{2}$ by measurement using the $\mathrm{LiAlH}_{4}$ method. ${ }^{13,14)}$

Since dry-type silica does not have much electrostatic repulsive force by $\mathrm{OH}$ groups in comparison with wet-type silica, it is thought that the former is easily condensed ${ }^{15)}$ and that the anchor effect is exhibited when an organic film is formed at the top of the pretreatment film. It is considered that the peel-off strength and adhesion at the bent section are improved as the $\mathrm{SiO}_{2} / \mathrm{Cr}$ mass ratio increases because the coverage of the rough film with the dry-type silica increases as shown in Fig. 12.

Furthermore, the reason why the adhesion improved as the particle size of the dry-type silica decreased is thought to be due to the increase in surface polarity and the increase in interface bonding sites for adhesion, as already reported ${ }^{6-8)}$ since nano-porous films with high specific surface area are formed as shown in Fig. 13, in addition to the anchor effect by the above-mentioned fine surface roughness.

\subsection{Improvement effect of adhesion by compositing chromate}

The dry-type silica (chromate-free) film B has lower coverage than the chromate pretreatment film with dry-type silica D2 for the same coating weight of $\mathrm{SiO}_{2}$ as shown in Fig. 9. In the case of the B film, since exfoliation occurred mainly at the interface between the pretreatment film and the adhesive film as shown in Fig. 8, the adhesion of the interface between the pretreatment film and zinc coating is suggested to be extremely weak. In the case of the $\mathrm{D} 2 \mathrm{film}, \mathrm{SiO}_{2}$ condenses toward the interface between the adhesive film and D2 film and $\mathrm{Cr}$ condenses toward the interface between the D2 film and zinc coating as shown in Fig. 10, and the $\mathrm{Cr}$ is assumed to be insoluble $\mathrm{Cr}$ (III) near the interface of the zinc coating. ${ }^{9-11)}$ Thus, the insoluble $\mathrm{Cr}(\mathrm{III})$ fixes $\mathrm{SiO}_{2}$ as binder and enhances the adhesion between the zinc coating and the pretreatment film. However, in the case of the silica-rich film with $\mathrm{SiO}_{2} / \mathrm{Cr}$ mass ratio of more than 4.0 , since the binder effect by $\mathrm{Cr}(\mathrm{III})$ condensing toward the lower part of the pretreatment film becomes insufficient and the part of $\mathrm{SiO}_{2}$ condensing toward the upper part of the pretreatment film is not fixed, the adhesion decreases.

\section{Conclusion}

The correlation between the composition of chromate pretreatment films with dry-type silica and the adhesion to an organic film on a zinc coated steel sheet was examined by measuring the peel-off strength after stretching and the adhesion at the bent section. The adhesion mechanism was also investigated morphologically at the sub-micron level and the surface area at the nano level by analyzing the pretreatment films using SEM, AFM, BET, TEM and EDX. The results are summarized as follows:

(1) Not only the type and particle size of silica, but also the silica/chromate ratio and the coexistence of chromate affected the adhesion of laminate films. The highest adhesive strength was obtained for the pretreatment films formed in a pretreatment solution with $\mathrm{SiO}_{2} / \mathrm{Cr}$ ratio of 4.0 and dry-type silica with a particle diameter of $7 \mathrm{~nm}$ which is equivalent to that of the zinc phosphate films widely used today.

(2) For the dry-type silica pretreatment films and chromate pretreatment films with wet-type silica which had poor adhesion, cohesive destruction occurred at the interfaces of the pretreatment film/zinc coating, and the adhesive film/pretreatment film respectively. In contrast, for the chromate pretreatment films with dry-type silica, cohesive destruction occurred across the interface of the pretreatment film and the adhesive film.

(3) Compared with the chromate pretreatment (silica-free) films and the chromate pretreatment films with dry-type silica, the dry-type silica pretreatment (chromate-free) films and the chromate pretreatment films with dry-type silica showed fine surface roughness. As the particle size of silica in the chromate pretreatment films with dry-type silica decreased, these specific surface areas increased remarkably.

(4) $\mathrm{Cr}$ condenses toward the interface of the pretreatment films/zinc coating, while $\mathrm{SiO}_{2}$ condenses toward the interface of the adhesive films/pretreatment films.

(5) Consequently, the good adhesion of chromate pretreatment films with dry-type silica is due to the action of the dry-type silica and the effect of the chromate. The action of the dry-type silica consists of an anchor effect by fine surface roughness and an increased number of interface bonding sites by high specific surface area due to the nano-level fine structure and nano-porous structure. The chromate serves to fix (a binder effect) the silica by insoluble $\mathrm{Cr}$ (III). 


\section{REFERENCES}

1) Y. Mitsuzawa and K. Ozawa: Collected Abstracts of the 73rd Meeting of Metal Finishing Society, (The Surface Finishing Society of Japan, 1986) p. 373

2) A. Yauchi, T. Usuki, T. Shiota and M. Nishihara: Tetsu-to-Hagane 72 (1986) S1313.

3) T. Shiota, A. Yauchi and Y. Yoshikawa: CAMP-ISIJ 1 (1988) 679.

4) Y. Kawanishi and N. Suzuki: CAMP-ISIJ 4 (1991) 1661.

5) T. Katsumi, K. Saito and Y. Miyauchi: CAMP-ISIJ 5 (1992) 691.

6) M. Nakazawa: J. Jpn. Soc. Colour Mater. 68 (1995) 424-433.

7) M. Nakazawa and M. Yoneno: Tetsu-to-Hagane 77 (1991) 115-122.

8) M. Nakazawa and M. Yoneno: Tetsu-to-Hagane 77 (1991) 406-413.
9) Y. Yoshikawa and J. F. Watts: Surf. Interface Anal. 20 (1993) 379384.

10) M. Miyaoka, M. Ishihara and K. Yoshihara: Collected Abstracts of the colour material annual technical meeting, (Japan Society of Colour Material, 1993) p. 119.

11) H. Noro, N. Okude and M. Nagoshi: Tetsu-to-Hagane 89 (2003) 109115.

12) J. D. Venables: J. Mater. Sci. 19 (1984) 2431-2453.

13) H. J. Wartmann: Dissertation ETH Zürich, (1958)

14) R. Bode, H. Ferch and H. Fratzscher: Kautschunk und Gummi Kunststoffe 20 (1967) 578-586.

15) G. B. Alexander: Silica and Me, (Tokyo Kagaku Dozin, Tokyo, 1971) p. 126. 